\title{
Recombinant Growth Factor
}

National Cancer Institute

\section{Source}

National Cancer Institute. Recombinant Growth Factor. NCI Thesaurus. Code C530.

Formulated therapeutic proteins that are either isolated from endogenous sources or manufactured in a laboratory. Growth factors bind to specific receptors expressed by various cell types, thereby stimulating cell differentiation and/or proliferation. (NCI04) 